\title{
Radiobiological Study of Retinal Microvessel Proliferation in Diabetic-like Rat Model
}

\author{
Xiao W. Mao*, Pierre Archambeau, Waheed K. Baqai, Shaun Larsen and John O. Archambeau
}

Radiation Biology Lab, Department of Radiation Medicine, Chan Shun Pavilion, Room A-1010, 11175 Campus Street, Loma Linda, CA 92354, USA

\begin{abstract}
Progressive evolution of retinal vascular in diabetic retinopathy leads to blindness in up to 8,000 patients yearly. The major purpose of this investigation was to determine proton radiation dose response of the eye's retinal vasculature in the hypergalactosemia induced rat model of diabetic-like retinopathy and gain insight of possible role of proton radiotherapy in controlling diabetic retinopathy. A single dose range of proton radiation $(8,14$, and 20 Gy) was delivered to one eye of each rat at 4 months following induction of hypergalactosemia. The opposite eye of each rat, which was not irradiated, showed normal progression of retinopathy. Stereologic techniques were used to quantify tissue parameters in situ in a retinal digest preparation that allowed unobstructed access to the vasculature. 15 months following $50 \%$ galactose diet, characteristic histopathological lesions of retinopathy such as capillary endothelial cell proliferation, capillary closure, capillary microaneurysms, pericyte loss developed in non-irradiated eyes. The endothelial cell densities for rat receiving $50 \%$ galactose diet were significantly higher than that of control $(\mathrm{p}<0.05)$. Proton irradiation inhibited significant endothelial cell proliferation at dose from $14 \mathrm{~Gy}$ to $20 \mathrm{~Gy}$ ( $\mathrm{p}<0.05$ ), yet not diminished pericyte loss at current dose schedule. These findings indicated beneficial effects of proton radiation on hypergalactosemia induced diabetic-like retinopathy. Our study should have an impact on further studies to optimize radiation treatment strategies for diabetic retinopathy.
\end{abstract}

Keywords: Proton radiation, retinal microvessel, diabetic-like model, proliferation, stereology.

\section{INTRODUCTION}

\section{Overview}

Proliferative vascular disorders of the eye are a major contributor to blindness in both diabetic retinopathy and subfoveal neovascular membrane (SNFM) formation [1-3]. Both diseases are likely to increase in the coming two decades as the "baby boom generation" enters its 60s and 70s. Diabetic retinopathy shows a progressive evolution of retinal vascular changes that leads to blindness [4].

Published reports of LLU clinical Phase I/II dose escalation study (efficacy and safety) for therapy of subfoveal neovascular membrane formation (SFNM) report arrest of the progression of the visual loss and control of the membrane formation in $90 \%$ of 300 patients with an average three year follow-up [5-7]. Thus, proton radiotherapy has become a promising, innovative alternative strategy for controlling vision loss due to SFNM.

\section{Microvessel Changes in Response to Irradiation}

The dose dependent loss of microvessel length and cell density with vessel dilatation characterized the radiation changes in microvessels of swine dermis and in patients [811]. A dose and time dependent loss of endothelial cells, but not of pericytes was also noted [12-15]. Vessel stranding occurred, but not tissue necrosis.

*Address correspondence to this author at the Radiation Biology Lab, Department of Radiation Medicine, Chan Shun Pavilion, Room A-1010, 11175 Campus Street, Loma Linda, CA 92354, USA;

E-mail:xmao@dominion.llumc.edu

\section{Progression of Diabetic-Like Retinopathy}

Among the changes considered to document this proliferation are the presence and increasing numbers of microaneurysms, hypercellular shunts, increased number of microvessels, and increased number of endothelial cells focally in the central retina [16-19]. These are logical associations but cellular proliferation has not been documented as such. The formations of pericyte ghosts, loss of pericytes and endothelial cells with the formation of many acellular vessel strands were documented during the first 7 months following galactose feeding [20-24].

Although galacotsemic rats are not diabetic [25] -- the insulin levels are physiological and glucose continues to be metabolized -- they are an excellent preclinical animal model of diabetic-like retinopathy. The etiologic agent is galactitol which is not metabolized and increases to high levels in the blood. Galactation of proteins is produced in cells resulting in deposition of glycans (galactan) in basement membranes. Galactitol is also osmotically active producing cataracts and rupture of pericytes [26]. Fluorescein angiography (in dogs) $[27,28]$ and retinal digests document a symptom producing increase in number of vessels (branching), formation of microaneurysms, vessel torturosity and shunt formation by 1624 months [29-31]. The microaneurysams and cellular shunts occur, but they do not occur uniformly in all animals or in time or throughout the whole retina. The highest density of proliferative changes was found in the posterior retina surrounding the optic nerve from several studies [32].

The objective of the investigation was to determine the proton radiation dose response of the eye's retinal vasculature and gain insights into the radiobiologic and therapeutic 
mechanism of action of proton radiation. Our preclinical model is hypergalactosemia induced diabetic-like retinopathy in laboratory rats. The morphological changes produced are similar to those reported for diabetic retinopathy in humans. This model was selected as the bioassay for diabetic retinopathy because it would enable us to anticipate the possible effects in humans.

Stereologic techniques were used to quantify tissue parameters in situ in the retinal digest preparation that allowed unobstructed access to the vasculature. Endothelial cell and pericyte cell number were determined; vessel density, microvessel profile area and length were measured.

\section{MATERIALS AND METHODS}

\section{Animals}

A total of 90 weanling male Sprague-Dawley rats, each weighing about 50 grams, were purchased locally and maintained, three per cage, under constant ambient temperature of $65^{\circ} \mathrm{F}$ with a twelve-hour day/night cycle. Water and a diet with $50 \%$ content of galactose or $50 \%$ starch were available ad libitum. Rats' body weights were monitored at monthly intervals and the animals were observed daily for signs of radiation-related toxicity. Rapid $\mathrm{CO} 2$ asphyxiation was performed in compliance with the NIH Guide for the Care and Use of Laboratory Animals.

\section{Proton Irradiation}

Irradiation was performed 4 month following $50 \%$ galactose or $50 \%$ starch diet. Each eye was irradiated with a modulated and shaped $100-\mathrm{MeV}$ proton beam, using dose schedules of $0,8,14$ and $20 \mathrm{~Gy}$. The dose was chosen from our previous experience and clinically dose schedule [33]. Rats were positioned in the path of the beam using a cardboard holder after being anesthetized with 0.3 cc Ketamine:Xylazine mixture $(5: 2)$ via intraperitoneal injection. Field localization is achieved using a $0.8 \mathrm{~mm}$-diameter light field projected through the beam nozzle to the (iso)center. Protons were delivered in 300-millisecond pulses every 2.2 seconds, yielding an average dose rate of $7 \mathrm{~Gy} / \mathrm{min}$.

\section{Retinal Digest Preparation}

The rats were euthanasia 15 month following proton irradiation (19 month following the diet). The retina was re-

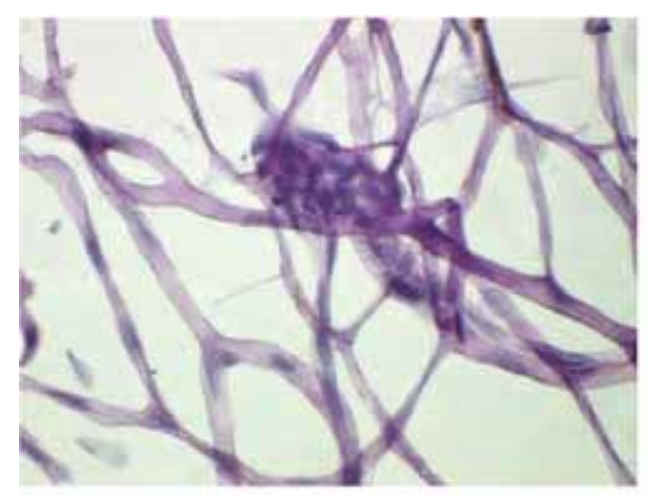

A moved from eyes and fixed at room temperature for at least 4 days by immersing the whole eye in $4 \% \mathrm{w} / \mathrm{v}$ paraformaldehyde in $50 \mathrm{mmol} / 1$ sodium/potassium phosphate buffer with $4 \%$ sucrose at pH 7.2 using Laver's detailed approach [34]. The entire retina was mounted on the microscope slide.

\section{Stereology}

The dose response of the retinal digest microvasculature was determined using stereologic analysis. Digest was used for stereologic enumeration on an Olympus Computer Assisted Stereological Toolbox system (The Olympus C.A.S.T.-Grid system, Denmark). In order to have an equal probability that any part of the retina was sampled, the retinal digest perimeter was drawn. Then, using the stereological software grid system stepping function, the surface area was divided into a designated number of equal area "pixels" or steps. The number was designated by determining the number of steps required to permit a fixed number of counts or intersections to be made. Generally, 200 steps (counting areas) are sufficient. A series of point, line, and area probes calculations was used to determine area (points), length (line probes) and cell enumeration (area probes or counting frames of known area) endothelial cell and pericyte density.

\section{Endothelial Cells and Pericytes}

The endothelial cells are distinguished from pericytes using criteria described in the pilot study [35]. The endothelial cell faced the lumen; the pericytes were found outside the basement membrane. They were smaller and more deeply stained than endothelial cells.

\section{Statistical Methods}

An $80 \%$ power analysis indicated that for a definitive statistically conformal protocol at least 6 animals were used for statistical comparison in each irradiated group and in the unirradiated group. A statistical comparison between parameter means can be made at control, 8Gy, 14Gy and 20Gy. Results were subjected to statistical analyses including oneway analysis of variance (ANOVA) and Tukey's HSD (honestly significant difference) test using SigmaStat ${ }^{\mathrm{TM}}$ version 3.5 software (SPSS Inc., Chicago, IL). A p value of $<0.05$ was selected to indicate significant differences among groups.

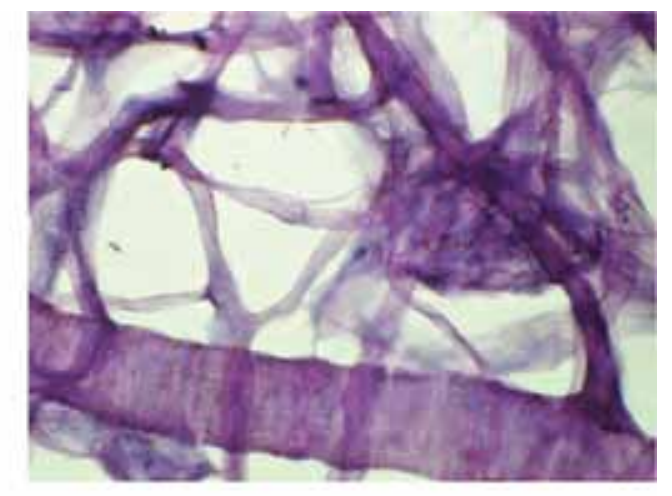

B

Fig. (1). Hypergalactosemic-induced microaneuysms in rat retinas from rats fed 50\% galactose for 19 months (15 months after radiation) (Original magnifications 40X). A: Cylindrical type, this microaneurysm occurred near the middle of the capillary plexus. B: Irregular type, this microaneurysm occurred in close association with the artery. 


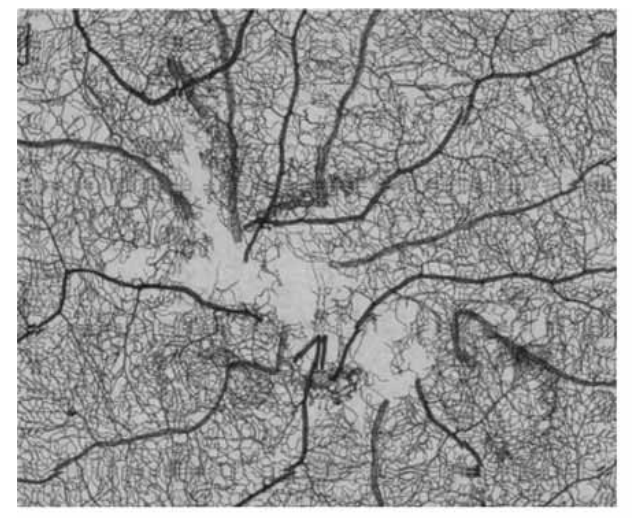

A

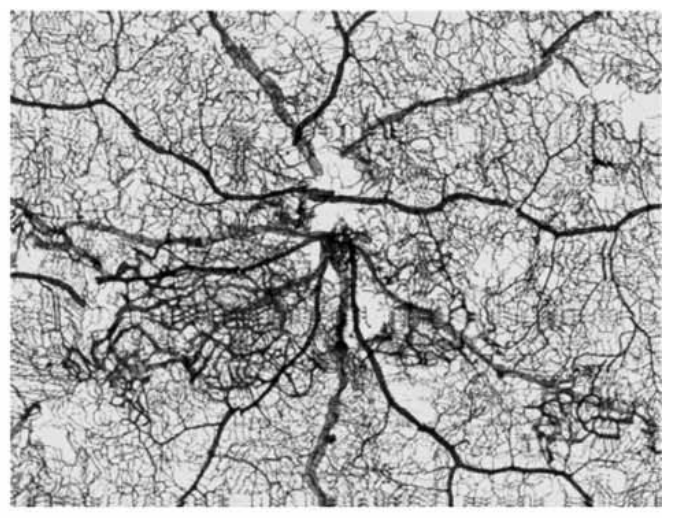

B

Fig. (2). Flat mount of rat retinal microvessels (original magnification 10X). A) Fed 50\% starch for 19 months beginning at weanling. All capillaries appeared normal. B) Fed 50\% galactose for 19 months beginning at weanling. Vessel proliferations were shown in central retina surrounding optic disc.

\section{RESULTS}

\section{Microaneurysm}

Microaneurysm formation (Fig. 1) was observed around 15 to19 months in galactose-fed rats. Different types of microaneurysms have been noticed in our study. Cylindrical or irregular type with vessel dilation was shown in Fig. (1A) and Fig. (1B) respectively. Fewer microaneurysms were seen in galactose-fed rat received irradiation. A proliferation of endothelial cells and focal dilation of capillaries resulted in microaneurysms. By contrast, other capillaries which were adjacent, maintained a normal diameter or lost their endothelia cell and percyites, and became acellular, non-functional stranding. Vessel proliferations in 50\% galactose-fed rat were shown in central retina surrounding optic disc (Figs. 2A, 2B).

\section{Microvessel Morphology Changes}

Changes in the retinal vasculature following radiation and the 50\% galactose diet are shown in Fig. (3). In the control retina (Fig. 3A), the normal capillaries had a uniform caliber and smooth contour. Two populations of cells were abundant in the vessel wall: endothelial cells and pericytes. Retina from galactose fed rats showed irregular capillary contour with stranding. (Fig. 3B) Vessel walls were hypocellular in pericytes. Staining variations were noted between the control and galactose retinal vessel. The variations were attributed to variations in the thickness of basement membrane. Changes in contours may be explained from loss of pericytes.

\section{Microvessel Cell Population}

The retinal vessel digest provided excellent twodimensional visualization of the microvasculature of the rat retina. Following irradiation, the total retinal pericyte counts in rats receiving $50 \%$ galactose diet were significantly lower than the counts for the $50 \%$ starch $\operatorname{diet}(\mathrm{p}<0.05)$ following 14 and $20 \mathrm{~Gy}$ of proton irradiation at 15 months (Fig. 4). The slope of the pericyte cell population regression line from rats receiving 50\% galactose was greater than that for 50\% starch diet. At 15 months, the endothelial cell density for nonirradiated control rat receiving 50\% galactose diet was significantly higher than that starch diet $(\mathrm{p}<0.05)$. Endothelial

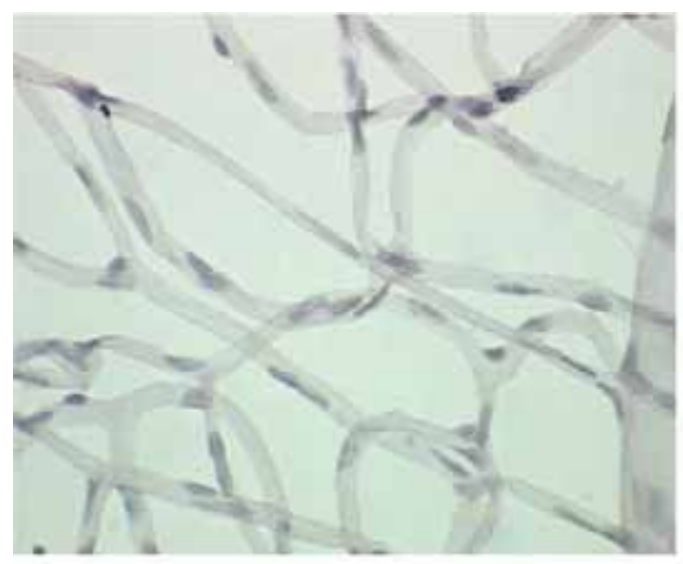

A

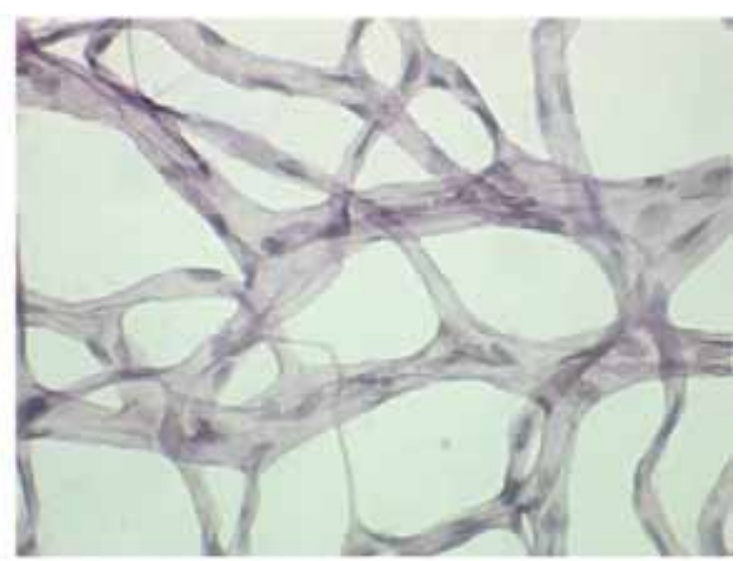

B

Fig. (3). Microvessel network in rat retinas (original magnification 40X). A) Normal structure of the retina capillary network was maintained with normal endothelial cell and pericytes from a rat fed 50\% starch for 19 months. B). Cell population and morphological changes in rat retina from a rat fed $50 \%$ galactose for 19 months showed focal dilations of the capillary and focal proliferation of the endothelial cells. Stranding was evident in the center of the image. 
cell densities in galactose fed non-irradiation control rats were significantly high than that of rats fed with galactose diet receiving 14 and $20 \mathrm{~Gy}$ of irradiation. $(\mathrm{p}<0.05)$ (Fig. 5). Dose dependent cell loss was seen at galactose-fed rats receiving 8 to $20 \mathrm{~Gy}$ of proton radiation.

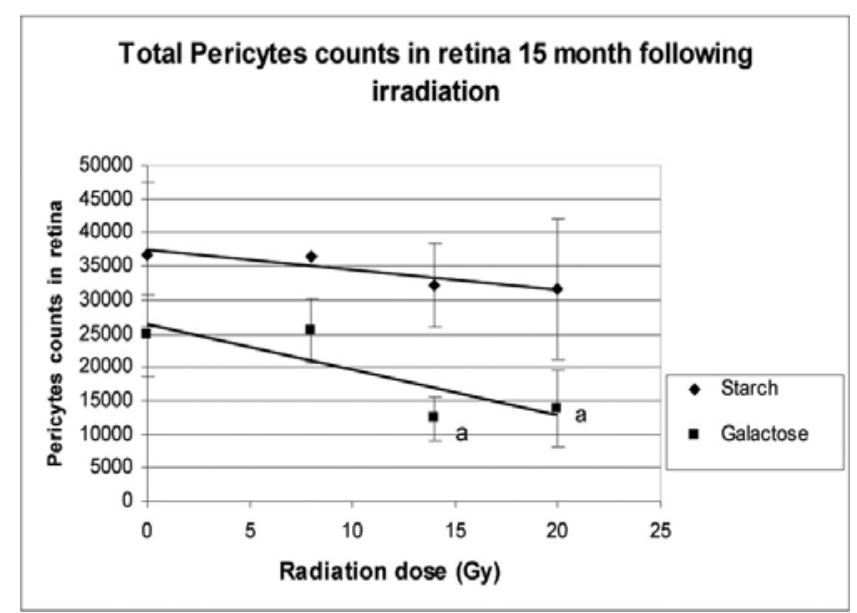

Fig. (4). Total pericytes in retina of age matched control eyes and eyes received irradiation 15 months earlier of starch-fed and galactose - fed rats. At 15 months following irradiation, pericytes in galactose -fed retina were significantly lower than starch-fed rat at all dose $(0,8,14$ and 20Gy) $(\mathrm{p}<0.05)$.

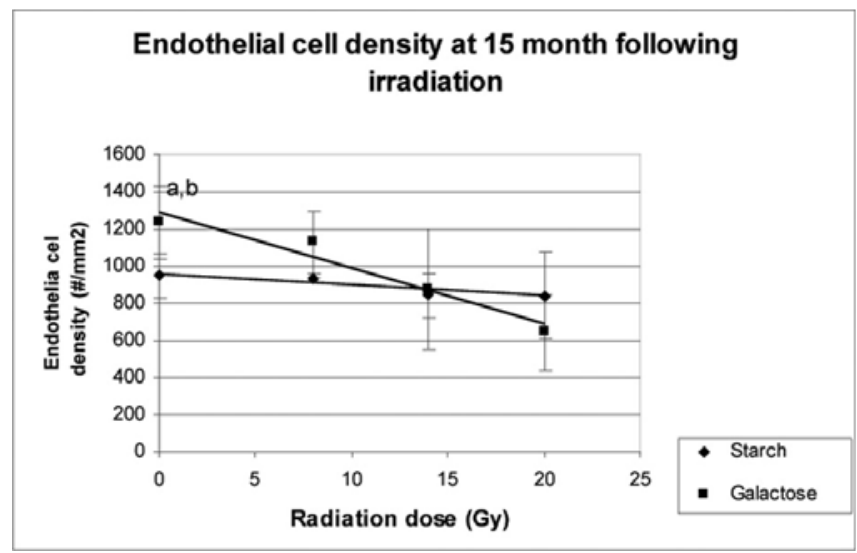

Fig. (5). Endothelial cell densities in retina of age matched control eyes and eyes received irradiation 15 months earlier of starch-fed and galactose -fed rats. ${ }^{\text {a }}$ Endothelial cell density in galactose fed non-irradiation control rats significantly high than that of starch fed rats. ${ }^{b}$ Endothelial cell density in galactose fed non-irradiation control rats significantly high than that of rats fed with galactose diet receiving 14 and 20Gy of irradiation $(\mathrm{p}<0.05)$.

\section{Microvessel Length}

The vessel length densities were not significantly different among groups fed with $50 \%$ glasctose diet or rats fed $50 \%$ starch diet following $8 \mathrm{~Gy}, 14 \mathrm{~Gy}$ and $20 \mathrm{~Gy}$ of proton irradiation (Fig. 6). The tendency of dose dependent vessel loss was shown in galactose rats following irradiation.

\section{Retina Area}

The total retinal area increased with age in starch-fed rats, ranging from 42 to $79 \mathrm{~mm}^{2}$ at 1 to 15 months following irradiation. Retinal growth was arrested in rats fed with galactose (Table 1). From 6 to 15 months, the difference in retinal area between rats fed with galactose and starch was significant $(\mathrm{P}<0.05)$.

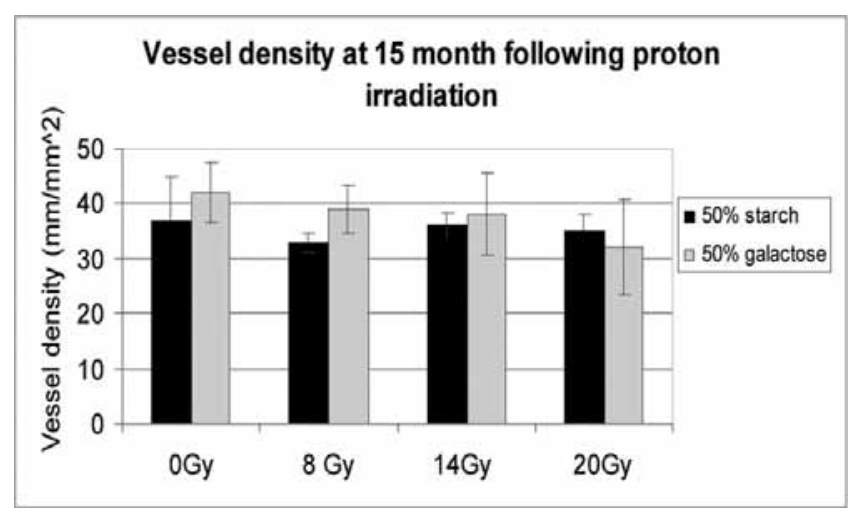

Fig. (6). Microvessel lengths density in the $50 \%$ starch-fed or galactose-fed retina 15 months following irradiation at each dose schedule.

\section{DISCUSSION}

Our main objectives of this lab were to study and quantify the architectural and population changes in microvessels after radiation. Our previous emphasis was directed to the quantification of normal, quiescent microvessels and their population in the rat retina model. A progressive time and dose-dependent endothelial cell loss were seen over 15 to 24 months following proton irradiation at 8, 14, 20 and 28Gy dose schedules. No proliferation was documented over two year observation period. Rat retinal vasculature was proved to be a slow responding, non-proliferative tissue [35]. It raised question of radiation dose response of proliferative microvasculature. The main focus of the present study was to quantify proton dose response of proliferative retinal vasculature in the hypergalactosemia induced rat model of diabetic-like retinopathy.

The hypergalactosemia induced diabetic-like retinopathy produces morphological changes similar to those reported for man. It was selected as the bioassay because it would permit the investigators to anticipate what the possible role would be in irradiating man. The hypergalactosemia induced rat model was also selected because it permited defining a generic model that could give insight into the response of proliferating microvasculature.

While it is convenient and useful to characterize and combine the morphological changes into a descriptive sequence, it remains an oversimplification. Certainly, the initial cell loss, vessel stranding (degenerative phase) ending in a designated distorted vasculature does not confirm that a hypoxic environment is created. It is, however, attractive to associate these changes as etiologic for the subsequent "regenerative" or proliferative phase characterized by the formation of microaneurysms, cellular shunts, vessel dilation, increased number and length of microvessels and endothelial cells. While these changes may represent proliferation, it is not known if the process results from angiogenesis or a vasculogenesis resulting from circulating angioblasts (stem cells). Equally important, there is no explanation for the 
Table 1. Total Retinal Area $\left(\mathrm{mm}^{2}\right)$ was Estimated by Measuring an Opened Hemispherical Globe that Contained the Retina Using Computer Assisted Stereological Toolbox (CAST).

\begin{tabular}{|c|c|c|c|c|c|}
\hline \multicolumn{3}{|c|}{ Weanling Galactose } & \multicolumn{2}{c|}{ Weanling Starch } \\
\hline Time (months) & $\mathbf{0 G y}$ & $\mathbf{1 4 G y}$ & Time (months) & 0Gy & 14Gy \\
\hline \hline 1 & $47+/ 3.3$ & $46+/-5.2$ & 1 & $42.2+/-3.5^{\text {a }}$ & $42.5+/-3.5^{\text {b }}$ \\
\hline 6 & $52+/-4.4^{\mathrm{c}}$ & $49+/-3.1$ & 6 & $77.2+/-0.9$ & $59+/-6.8$ \\
\hline 15 & $55+/-2.7^{\mathrm{c}}$ & $52+/-3.4^{\mathrm{d}}$ & 15 & $79+/-1.7$ & $63+/-4.2$ \\
\hline
\end{tabular}

Retinal size increased with age in 50\% starch fed rats but remained unchanged in non-irradiated 50\% galactose fed rats. Significant difference was seen between galactose fed and starch fed rats in both control and irradiated rats. ${ }^{a}$ Significantly smaller than that of 6 and 15 months following irradiation (p<0.05). ${ }^{b}$ Significantly smaller than that of 6 and 15 months ( $\mathrm{p}<0.05)$. ${ }^{\mathrm{c}}$ Significantly smaller than starch control $(\mathrm{p}<0.05){ }^{\mathrm{d}}$ significantly smaller than that of starch diet following $14 \mathrm{~Gy}$ of radiation at 15 months.

close proximity of these changes to large vessels or for the unequal distribution of change in the retina.

The study was well designed and the morphologic parameters could be quantified. This permitted distinguishing the total cellularity in the retina and the change of area involved. Also, it was possible to distinguish a difference between a rapid cell loss of $2-4 \%$ of cells per day of an acutely responding proliferation from a slowly proliferating population losing $0.1 \%$ of cells per day. These parameters allowed a decision to be made about the efficacy of the irradiation.

In this present study, at four months, endothelial cells and capillary density due to galactose diet were increased compared to that of starch diet. Following irradiation, dose response for galactose-altered retina is significantly greater than starch-fed control retina. It was suggested that proliferative stimuli were active at that time.

Subsequent to selective perictes loss, the other important histopathological lesions are: endothelial cell proliferation, microaneurysms, and capillary closure [36]. Capillary proliferation was seen in our study, but the total endothelial cell and pericytes count from rats receiving $50 \%$ glalactose diet were decreased compared to their counterparts on $50 \%$

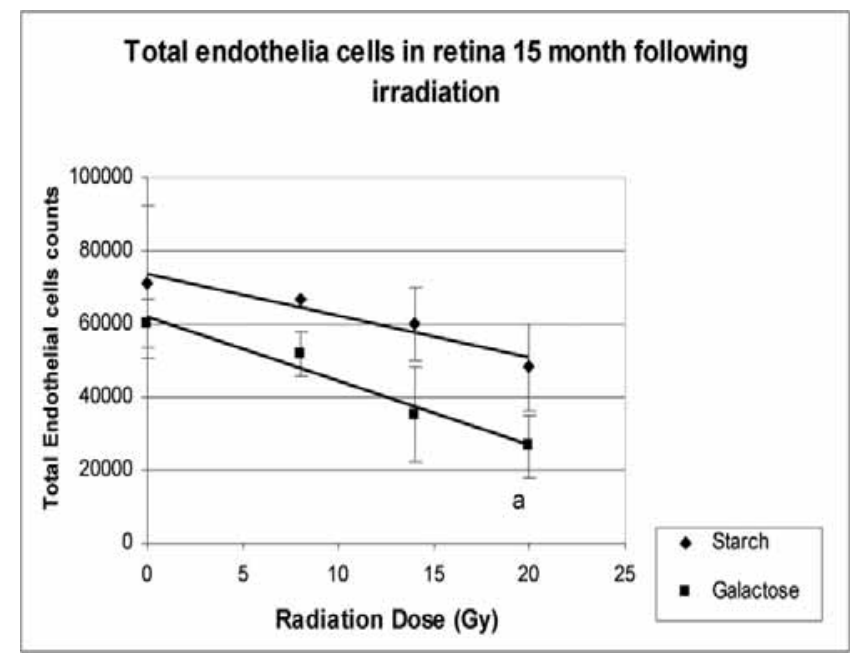

Fig. (7). Total endothelial cells in retina of age matched control eyes and eyes received irradiation 15 months earlier of starch-fed or galactose-fed rats. At 15 months, total endothelial cells in galactose - fed retina were significantly lower than that of starch-fed rat at higher doses (14 and 20Gy) $(\mathrm{p}<0.05)$. starch diet. This could be explained that endothelial cell and capillary proliferation are companied by selective endothelial cell and capillary loss in surrounding area. When total number of cells in the retina was counted, increase in cell number was not shown (Fig. 7).

\section{CONCLUSION}

1. Galactose diets suppress weight gain in weanlings and arrest the retina growth.

2. Selective pericyte loss is one of the histopathological lesions that are essentially unique to diabetic-like retinopathy. Proton irradiation at current dose does not prevent retinal pericyte loss.

3. Microaneurysms and focal endothelial cell proliferation were seen in galactose fed weanling rats. Relatively fewer microaneurysms were shown in irradiated retina from rats received $50 \%$ galactose diet for 4 months before radiation.

4. Irradiation alleviated or inhibited vessel proliferation in hypergalactosemia induced rat retina with dose dependence.

\section{ACKNOWLEDGEMENTS}

The authors thank Steve Rightnar for technical support. The study was supported in part by the National Aeronautics and Space Administration and Department of Radiation Medicine of the Loma Linda University Medical Center

\section{REFERENCES}

[1] Campochiaro PA, Soloway P, Ryan SJ, Miller JW. The pathogenesis of choroidal neovascularization in patients with age-related macular degeneration. Mol Vis 1999; 5: 34-39.

[2] Campochiaro PA. Retinal and choroidal neovascularization. J Cell Physiol 2000; 184: 301-310.

[3] Archambeau JO, Mao XW, Yonemoto LT, et al. What is the role of radiation in the treatment of subfoveal membranes: review of radiobiologic, pathologic, and other considerations to initiate a multimodality discussion. Int J Radiat Oncol Biol Phys 1998; 40:11251136.

[4] Fonseca V, Munshi M, Merin LM, Bradford JD. Diabetic Rethinopathy:A review for the primary care physician. South Med J 1996; 89: 839-850.

[5] Yonemoto LT, Slater JD, Friedrichsen EJ, et al. Phase I/II study of proton beam irradiation for the treatment of subfoveal choroidal neovascularization in age-related macular degeneration: treatment techniques and preliminary results. Int J Radiat Oncol Biol Phys 1996; 36: 867-871.

[6] Yonemoto LT, Slater JD, Blacharski PB, et al. Dose response in the treatment of subfoveal choroidal neovascularization in age- 
related macular degeneration: results of a phase I/II dose- escalation study using proton radiotherapy. J Radiosurg 2000; 3: 49-56.

[7] Moyers MF, Galindo RA, Yonemoto LT, et al. Treatment of macular degeneration with proton beams. Med Phys 1999; 26: 777-782.

[8] Archambeau JO, Ines A, Fajardo LF. Correlation of the dermal microvasculature morphology with the epidermal and the endothelial population changes produced by single $\mathrm{X}$ ray fractions of 1649 , 2231 and 2619 rad in swine. Int J Radiat Oncol Biol Phys 1985; 11: $1639-1646$.

[9] Archambeau JO. Swine skin: a model to evaluate dose recovery from different radiations. Basic Life Sci 1989; 50: 9-20.

[10] Archambeau JO, Pezner R and Wasserman T. Pathophysiology of irradiated skin and breast. Int J Radiat Oncol Biol Phys 1995; 31: 1171-1185.

[11] Turesson I. Characteristics of dose-response relationships for late radiation effects: an analysis of skin telangiectasia and of head and neck morbidity. Radiother Oncol 1991; 20: 149-58.

[12] Gordon KB, Char DH and Sagerman RH. Late effects of radiation on the eye and ocular adnexa. Int J Radiat Oncol Biol Phys 1995; 31: 1123-39.

[13] Archer DB. Doyne Lecture. Responses of retinal and choroidal vessels to ionising radiation. Eye 1993; 7: 1-13.

[14] Archer DB, Amoaku WM, and Gardiner TA. Radiation retinopathy--clinical, histopathological, ultrastructural and experimental correlations. Eye 1991; 5: 239-251.

[15] Archer DB. Bowman Lecture 1998. Diabetic retinopathy: some cellular, molecular and therapeutic considerations. Eye 1998; 13: 497-523.

[16] Robison WG, Laver N, Lou MF. The role of aldose reductase in diabetic retinopathy: Prevention and intervention studies. In: Osborne NN, Chader GJ, Eds., Progress in retinal and eye research. Vol. 14, Pergamon Press, Oxford, 1995: 593-640.

[17] Robison WG Jr., Jacot JL, Glover JP, Basso MD, Hohman TC. Diabetic-like retinopathy: early and late intervention therapies in galactose-fed rats. Invest Ophthalmol Vis Sci 1998; 39: 1933-41.

[18] Robison WG, Laver NM, Jacot JL, Chandler ML, York BM, Glover JP. Efficacy of treatment after measurable diabetic like retinopathy in galactose-fed rats. Invest Ophthalmol Vis Sci 1997; 38: 1066-1073.

[19] Takahashi Y, Augustin W, Wyman M, Kador PF. Quantitative analysis of retinal vessel changes in galactose-fed dogs. J Ocul Pharmacol 1993; 9: 257-269.

[20] Frank RN. On the pathogenesis of diabetic retinopathy. Ophthalmology 1984; 91: 626-634.

[21] Frank RN, The galactosemic dog. A valid model for both early and late stages of diabetic retinopathy. Arch Ophthalmol 1995; 113: $275-276$.
[22] Canivet J, Cruz A, Moreau-Lalande H. Biochemical abnormalities of the human diabetic glomerular basement membrane. Metabolism 1979; 28: 1206-1210.

[23] Robison WG, Kador PF, Kinoshita JH. Retinal capillaries: basement membrane thickening by galactosemia prevented with aldose reductase inhibitor. Science 1983; 221: 1177-1179.

[24] Robison WG, Kador PF, Akagi Y, Kinoshita JH, Gonzalez R, Dvornik D. Prevention of basement membrane thickening in retinal capillaries by a novel inhibitor of aldose reductase, tolrestat. Diabetes 1986; 35: 295-299.

[25] Robinson WG, Laver NM, Jacot JL, et al. Diabetic-like retinopathy ameliorated with aldose reductase inhibitor WAY-121,509. Invest Ophthal Vis Sci 1998; 37: 1149-1154.

[26] Robison WG. Diabetic retinopathy: galactose-fed rat model. Invest Ophthalmol Vis Sci 1995; 36: 1743-1744.

[27] Engerman R. Diabetes like preproliferative retinal changes in galactose-fed dogs. Arch Ophthalmol 1993; 110: 584-585.

[28] Engerman RL and Kern TS. Retinopathy in galactosemic dogs continues to progress after cessation of galactosemia [see comments]. Arch Ophthalmol 1995; 113: 355-358.

[29] Takahashi JB, Hoshimaru M, Kikuchi H, Hatanaka M. Developmental expression of trkB and low-affinity NGF receptor in the rat retina. Neurosci Lett 1993; 151: 174-177.

[30] Takagi H, King GL, Ferrara N, Aiello LP. Hypoxia regulates vascular endothelial growth factor receptor KDR/Flk gene expression through adenosine A2 receptors in retinal capillary endothelial cells. Invest Ophthalmol Vis Sci 1996; 37: 1311-21.

[31] Takagi H. Role of vascular endothelial growth factor in microvascular abnormalities in diabetic retinopath. Nippon Ronen Igakkai Zasshi 2000; 37: 603-6.

[32] Cogan DG. Ophthalmic manifestations of systemic vascular disease. Vol.III. W.B. Saunders Co., Philadelphia, PA, 1974; pp. 81180.

[33] Mao XW, Archambeau JO, Kubínová L, Boyle S, Petersen G, Grove R. Quantification of rat retinal growth and vascular population changes following single and split dose schedules of proton irradiation: translational study using stereology methods. Radiat Res 2003; 160: 5-13.

[34] Laver NM, Robison WG, Pfeffer BA. Novel procedures for isolating intact retinal vascular beds from diabetic humans and animal models. Invest Ophthalmol Vis Sci 1993; 34: 2097-104

[35] Archambeau JO, Mao XW, Oeinck O, et al. Dose response of rat retinal microvessel to proton dose schedules used clinically: A pilot study. Int J Radiat Oncol Biol Phys 2000; 48:1155-1166.

[36] Ashton N. Studies of the retinal capillaries in relation to diabetic and other retinopathies. Br J Ophthal 1963; 47: 521-538.

(C) Mao et al.; Licensee Bentham Open.

This is an open access article licensed under the terms of the Creative Commons Attribution Non-Commercial License (http://creativecommons.org/licenses/by-nc/3.0/) which permits unrestricted, non-commercial use, distribution and reproduction in any medium, provided the work is properly cited. 